\title{
TERAPI SEFT MENURUNKAN INTENSITAS KEBIASAAN MEROKOK DI KELURAHAN SAMBUTAN KOTA SAMARINDA
}

\author{
SEFT THERAPY REDUCES THE SMOKING HABIT INTENSITY \\ IN THE SAMBUTAN VILLAGE OF SAMARINDA
}

\author{
${ }^{1)}$ M. Aminuddin, ${ }^{2)}$ Iwan Samsugito, ${ }^{3)}$ Dwi Nopriyanto, ${ }^{4)}$ Rita Puspasari \\ 1,2,3,4) Prodi D3 Keperawatan Fakultas Kedokteran Universitas Mulawarman \\ Jalan Anggur No. 88 Samarinda 75123 Kalimantan Timur \\ Email: aminuddin@ fk.unmul.ac.id
}

\begin{abstract}
ABSTRAK
Jumlah perokok dari tahun ke tahun semakin meningkat. Negara Indonesia menempati urutan ketiga di dunia berdasarkan tingginya jumlah perokok setelah Cina dan India.Spriritual Emotional Freedom Technique (SEFT) merupakan terapi yang memadukan antara kekuatan spiritual dan energi psikologi, dan didapatkan efek pelipat gandaan (amplifying effect) serta dapat menurunkan intensitas kebiasaan merokok. Tujuan kegiatan ini adalah (1) meningkatkan pengetahuan masyarakat tentang bahaya rokok dan menigkatkan kesadaran untuk berhenti merokok, (2) menurunkan intensitas kebiasaan merokok masyarakat dengan terapi SEFT. Metode pelaksanaan yang digunakan adalah survei keluarga, pendidikan kesehatan dan terapi SEFT. Hasil pengabdian kepada masyarakat ini menunjukkan jumlah perokok di kelurahan Sambutan kota Samarinda masih tinggi. Didapatkan $420 \mathrm{KK}(48,4 \%)$ yang minimal memiliki satu orang anggota keluarganya yang merokok dan mayoritas (49,05\%) menghabiskan 1 bungkus perhari dengan lama merokok terbanyak lebih dari 10 tahun $(62,4 \%)$.Penyuluhan kesehatan dapat meningkatkan pengetahuan masyarakat tentang bahaya rokok dan diharapkan dapat meningkatkan kesadaran masyarakat untuk berperilaku sehat dengan berhenti merokok. Terapi SEFT dapat menurunkan intensitas kebiasaan merokok masyarakat di kelurahan Sambutan kota Samarinda.
\end{abstract}

Kata kunci: Merokok; Terapi SEFT; Sambutan

\begin{abstract}
The number of smokers from year to year is increasing. Indonesia ranks third in the world based on the high number of smokers after China and India. Spiritual Emotional Freedom Technique (SEFT) is a therapy that combines spiritual strength and psychology energy, and obtained an amplifying effect and can reduce the intensity of smoking habits. The objectives of this activity are (1) to increase public knowledge about the dangers of smoking and increase awareness to stop smoking, (2) to reduce the intensity of people's smoking habits with SEFT therapy. The implementation method used is a family survey, health education, and SEFT therapy. The results this activities shows that the number of smokers in the village of Sambutan in Samarinda is still high. There were 420 families (48.4\%) who had at least one family member who smoked, and the majority $(49.05 \%)$ spent one pack per day with the most smoking time more than ten years (62.4\%). Health education can increase people's knowledge about the dangers of smoking and are expected to increase public awareness of healthy behavior by quitting smoking. SEFT therapy can reduce the intensity of the smoking habits of people in the Sambutan village of Samarinda.
\end{abstract}

Keywords: Smoke; SEFT Therapy; Sambutan

Submitted : 14 January 2019 Revision : 28 June 2019 Accepted : 20 July 2019 


\section{PENDAHULUAN}

Merokok merupakan sebuah perilaku fenomenal yang sudah menjadi kebiasaan sebagian masyarakat. Para perokok bukannya tidak mengetahui bahaya rokok, namun mereka enggan untuk menghentikan kebiasaan merokok. Banyak informasi yang telah mereka terima, baik dari media cetak maupun elektronik, baik berupa poster, baliho maupun iklan di televisi tentang bahaya yang diakibatkan oleh rokok. Namun sayangnya kebiasaan merokok sangat sulit mereka tinggalkan.

Jumlah perokok dari tahun ke tahun semakin meningkat. Negara Indonesia menempati urutan ketiga di dunia berdasarkan tingginya jumlah perokok setelah Cina dan India. Jumlah perokok di Indonesiaberdasarkan riskesdas tahun 2013 berjumlah 24,3\% dari total penduduk atau sekitar 48,40 juta perokok (Kemenkes RI, 2015). Berbagai upaya telah dilakukan oleh lembaga dan instutusi pemerhati bahaya rokok, termasuk upaya pemerintah baik pemerintah pusat yang menetapkan peraturan pemerintah no 109 tahun 2012 maupun peraturan walikota Samarindano 51 tahun 2012 tentang kawasan tanpa rokok (KTR) pada fasilitas umum. Namun upaya tersebut belum mampu menurunkan jumlah perokok. Hal ini disebabkan berbagai faktor antara lain sosial budaya masyarakat, tingkat pendidikan, fasilitas pendukung kawasan tanpa rokok, serta pemberian sanksi yang kurang tegas (Riska, 2016). Berdasarkan hasil Survei yang dilakukan di kelurahan Sambutan kota Samarinda terdapat minimal satu anggota keluarga di 420 kepala keluarga dari 845 kepala keluarga yang merupakan perokok aktif sejak lebih dari 10 tahun $(62,4 \%)$, dengan jumlah rokok yang dihabiskan perhari 1 bungkus atau lebih dari 1 bungkus. Tingginya jumlah perokok aktif ini berpengaruh terhadap bertambahnya jumlah penderita TB paru. Setidaknya ditemukan 34 kasus baru penderita TB dengan riwayat merokok setiap tahunnya di kelurahan Sambutan Samarinda.

Peningkatan jumlah perokok ini juga berdampak pada bertambahnya jumlah kasus atau beban penyakit akibat bahaya rokok dan meningkatnya angka kematian akibat rokok. Diperkirakan pada tahun 2030, angka kematian akibat rokok dunia akan mencapai 10 juta jiwa. $70 \%$ angka tersebut tersebar di negara berkembang termasuk Indonesia. Saat ini kematian akibat rokok di negara berkembang berkisar $50 \%$ dan jika kecenderungan ini terus berlanjut maka akan didapatkan 650 juta penduduk yang meninggal akibat rokok (Kemenkes RI, 2015). Oleh karenanya perlu dilakukan pencegahan ataupun tindakan agar kebiasaan merokok ini dapat diturunkan angkanya.

Kebiasaan merokok disebabkan oleh banyak faktor yang dapat berasal faktor internal maupun eksternal. Sebagian perokok mengatakan awalnya hanya untuk coba-coba, agar dikatakan gentle pada perokok berusia remaja dan berbagai faktor lainnya seperti pengaruh, teman, orang tua, iklan dan lain lain. Kebiasaan merokok tidaklah datang secara tiba-tiba. Kebiasaan merupakan tindakan yang diulang secara terus menerus dan sebuah tindakan akan terjadi karena diawali oleh niat. Sehingga kebiasaan perilaku merokok bila kita urutkan dan mencari akar penyebabnya sesungguhnya adalah niat awal untuk merokok. Niat yang awalnya hanya coba-coba, ikutikutan inilah yang menyebabkan kebiasaan perilaku merokok terjadi pada sesesorang. Begitu pula jika seseorang ingin menghentikan kebiasaan merokok, maka niat yang kuat dan tulus sangat menentukan berhentinya seseorang dalam merokok disamping terapi berhenti merokok yang didapatkan dari prosesional terapis behenti merokok.

Salah satu terapi berhenti merokok yang dikembangkan di bidang ilmu psikologi adalah hipnoterapi. Hipnotis dipergunakan untuk menghentikan kebiasaan merokok dengan cara merubah perilaku dalam kondisi hipnosis. Pada saat kondisi seseorang terhipnosis, perokok tersebut diberikan sugesti berupa pengaruh buruk atau hal hal buruk tentang rokok, sehingga perokok tersebut harus menghentikan kebiasaan merokoknya. Selain hipnoterapi juga terdapat terapi yang menggunakan energi psikologis yang disebut terapi Spiritual Emotional Freedom Technique (SEFT). Terapi SEFT memadukan antara kekuatan spiritual dan energi psikologi, dan didapatkan efek pelipat gandaan (amplifying effect) (Zainudin, 2012). Terapi SEFT memiliki 
prinsip kerja seperti terapi akupuntur dan akupresur serta emotional freedom technique (EFT) namun terapi ini menambahkan konsep spiritual atau do'a saat melakukan terapi. Terapi SEFT menggabungkan 3 teknik dari 21 teknik dalam terapi komplementer yaitu akupresur, hipnoterapi dan spiritual/doa dan terbukti efektif menurunkan intensitas kebiasaan merokok (Sulifan \& Muhid, 2014). Tahapan terapi ini terbagi menjadi tiga tahapan yaitu set up, tune in dan tapping(Zainudin, 2012). Sehingga terapi SEFT ini dapat menjadi salah satu terapi komplementer yang dapat digunakan untuk mengatasi masalah kecanduan dalam merokok.

Tujuan kegiatan pengabdian kepada masayarakat ini adalah untuk (1) meningkatkan pengetahuan masyarakat tentang bahaya rokok dan menigkatkan kesadaran untuk berhenti merokok, (2) menurunkan intensitas kebiasaan merokok masyarakat dengan terapi SEFT.

\section{METODE}

Kegiatan pengabdian masyarakat dilaksanakan di kelurahan Sambutan bekerjasama dengan puskesmas Sambutan. Puskesmas sambutan merupakan puskesmas memiliki wilayah binaan sebanyak 64 RT. Kegiatan pelayanan masyarakat dilaksanakan di dalam dan di luar gedung. Selain itu kegiatan ini melibatkan ketua RT yang aktif dalam memobilisasi warga serta mengikut sertakan mahasiswa keperawatan Universitas Mulawarman.

Kegiatan pengabdian kepada masyarakat $(\mathrm{PkM})$ berhenti tmerokok dengan terapi SEFT terdiri dari 3 kegiatan yaitu survei keluarga, penyuluhan kesehatan tentang bahaya merokok dan terapi SEFT. Setelah mendapatkan ijin dari aparat wilayah setempat yang meliputi kecamatan Sambutan, kelurahan Sambutan serta berkoordinasi dengan puskesmas Sambutan kota Samarinda, maka kegiatan mulai dilakukan sejak tanggal 17 Desember sampai dengan 28 Desember 2018.

1. Kegiatan Survei Keluarga

Survei dilakukan pada tanggal 17-20 Desember 2018 pada 10 RT di wilayah kelurahan Sambutan kota Samarinda. Survei yang dilakukan bertujuan untuk mengumpulkan data kesehatan masyarakat khususnya data terkait kebiasaan merokok keluarga. Kuesioner survei menggunakan format Program Indonsesia SehatPendekatan Keluarga (PIS PK) Kemenkes RI yang telah dimodifikasi. Pengumpulan data dilakukan dari rumah ke rumah melibatkan mahasiswa prodi D3 Keperawatan (Gambar 1), sehingga dapat terkumpul sebanyak 845 responden.

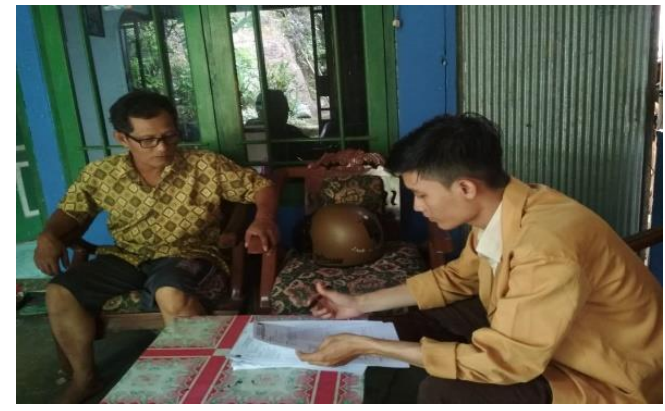

Gambar 1. Survei Keluarga

2. Kegiatan Penyuluhan Kesehatan Bahaya Rokok

Penyuluhan kesehatan dilakukan dibeberapa tempat di wilayah RT kelurahan Sambutan. Kegiatan ini bertujuan untuk meningkatkan pengetahuan masyarakat tentang bahaya rokok dan meningkatkan kesedaran masyarakat untuk berhenti merokok. Media dan alat penyuluhan menggunakan LCD proyektor dengan power point tentang rokok dan bahayanya serta film pendek bahaya merokok (Gambar 2).

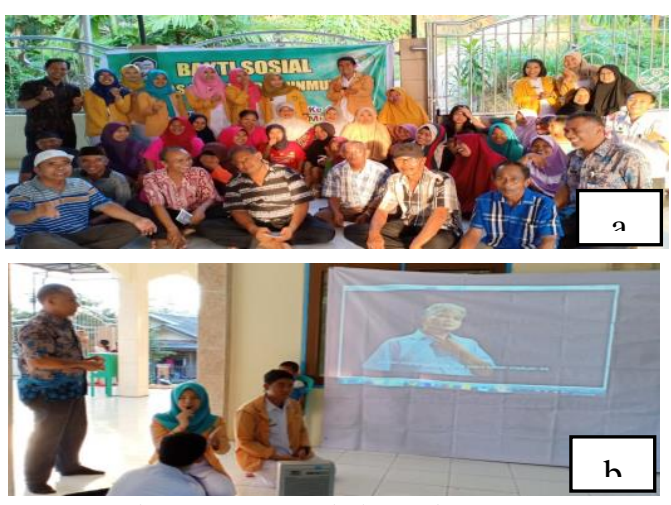

Gambar 2. Penyuluhan dan pemutaran film pendek tentang bahaya merokok

$(\mathrm{a}, \mathrm{b})$ 
3. Kegiatan Terapi SEFT

Terapi SEFT dilakukan pada tanggal 28 Desember 2018. Terapi SEFT dilakukan oleh praktisi yang telah mendapatkan pelatihanterdiri dari tiga tahap yaitu the set up, tune in dan tapping (Gambar 3). Tahap pertama the set upmerupakan tahapan dimana peserta diminta untuk berdo'a dengan ikhlas hanya kepada Allah SWT yang bertujuan agar aliran energi tubuh terarahkan dengan tepat. Kemudian yang kedua tune ini, tahap ini dapat juga disebut self hipnoterapy untuk menghapus informasi yang berada di alam bawah sadar yang menjadi energi negatif penyebab perilaku merokok. Pada tahap ini peserta diharapkan berdamai dengan masalahnya dan kemudian mengubahnya dengan halhal lebih positif. Tahap kegita adalah tapping dengan cara mengetuk ringan 18 titik dengan kedua jari. Ketukan ketukan ringan ini bertujuan untuk menetralisir gangguan emosi atau rasa nyeri yang dirasakan karena aliran energi tubuh kembali berjalan normal dan seimbang (Budianto, 2015; Zainudin, 2012).

Terapi SEFT dapat merelaksasikan dan membebaskan seseorang dari tekanan emosional yang menjadi salah satu faktor yang dapat menyebabkan seseorang ingin merokok, karena didalam rokok terkandung zat nikotin yang dapat merangsang hormon dopamin, endorpin dan serotonin yang berfungsi sebagai penenang(Blaise, Suriadi, \& Hafizah, 2015).
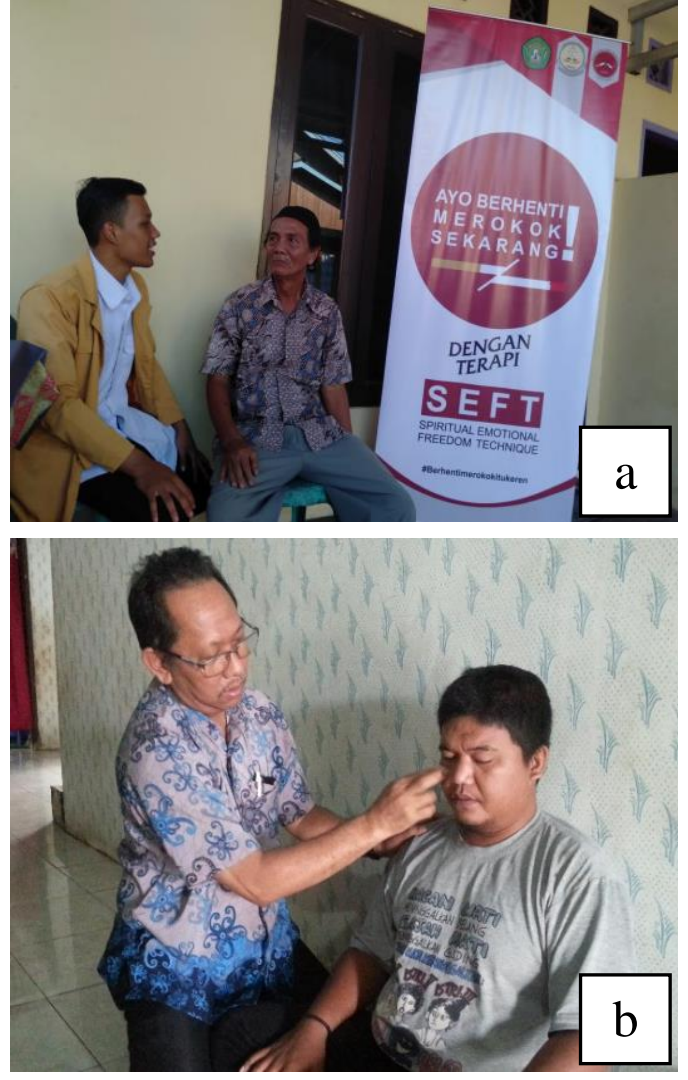

Gambar 3. Terapi SEFT tahapan set up (a) dan tapping (b)

\section{HASIL DAN PEMBAHASAN}

1. Survei Keluarga

Survei atau pengumpulan data keluarga yang dilaksanakan pada tanggal 17 s.d. 20 Desember 2018 menggunakan kuesioner PIS PK Kemenkes RI yang telah dimodifikasi. Survei dilakukan pada 845 kepala keluarga pada 10 RT di wilayah kelurahan Sambutan. Berdasarkan hasil tabulasi data didapatkan 420 keluarga $(48,4 \%)$ yang memiliki minimal satu anggota keluarga yang merokok dengan frekuensi merokok mayoritas 1 bungkus rokok perhari $(49,05 \%)$, bahkan terdapat $20,5 \%$ yang mengahbiskan lebih dari 1 bungkus perhari dan lainnya mengkonsumsi rokok kurang dari 1 bungkus perhari (tabel 1). 
M. Aminuddin, Iwan Samsugito, Dwi Nopriyanto, Rita Puspasari

Terapi Seft Menurunkan Intensitas Kebiasaan Merokok Di Kelurahan Sambutan Kota Samarinda

Tabel 1. Proporsi konsumsi rokok perhari pada keluarga di kel Sambutan, 2018

\begin{tabular}{cccc}
\hline No & Jumlah & Frekuensi & Persentase \\
\hline 1 & 1 batang & 48 & 11,40 \\
2 & $<1$ bungkus & 80 & 19,05 \\
3 & 1 bungkus & 206 & 49,05 \\
4 & $>1$ bungkus & 86 & 20,50 \\
& Total & $\mathbf{4 2 0}$ & $\mathbf{1 0 0 , 0 0}$ \\
\hline
\end{tabular}

Hasil tabulasi data juga menunjukkan bahwa sebagian besar $(62,4 \%)$ keluarga menyatakan bahwa anggota keluarganya sudah merokok lebih dari 10 tahun, selain itu 21,7 \% telah merokok 5-10 tahun, $13,8 \%$ merokok 1-5 tahun dan 2,1\% mulai merokok kurang dari 1 tahun terakhir (tabel 2).

Tabel 2. Proporsi lama merokok pada keluarga di kel. Sambutan, 2018

\begin{tabular}{cccc}
\hline No & Waktu & Frekuensi & Persentase \\
\hline 1 & $<1$ tahun & 9 & 2,1 \\
2 & $1-5$ tahun & 58 & 13,8 \\
3 & $5-10$ tahun & 91 & 21,7 \\
4 & $>10$ tahun & 262 & 62,4 \\
& Total & $\mathbf{4 2 0}$ & $\mathbf{1 0 0 , 0}$ \\
\hline
\end{tabular}

Tingginya jumlah perokok aktif di kelurahan Sambutan kota Samarinda kemungkinan dapat disebabkan karena kebiasaan merokok masyarakat sudah berlangsung lama (mayoritas lebih dari 10 tahun) dan sudah menjadi gaya hidup dan menjadi kebutuhan. Para perokok memiliki persepsi bahwa merokok merupakan suatu kegiatan yang menyenangkan dan dapat membuat fisiknya lebih bersemangat dan hati mereka bahagia. Sehingga tidak mudah bagi perokok untuk berhenti merokok tanpa dibarengi dengan keinginan diri yang kuat. Kalaupun ingin berhenti merokok biasanya akan dihadapkan oleh tantangan berupa perubahan fisik dan mental (Fawzani \& Triratnawati, 2005) seperti badan lemas, pusing, sakit kepala, akral dingin, gelisah dan perasaan tidak nyaman serta gejala lainnya.

Sementara itu, keluarga juga menyatakan bahwa perokok yang terdapat dalam keluarga sering mengeluh batuk dan sesak napas $(45,9 \%)$. Berdasarkan keinginan untuk berhenti merokok, mayoritas keluarga $(57,6 \%)$ menyatakan ingin berhenti merokok.
2. Penyuluhan Kesehatan

Penyuluhan kesehatan dan pemutaran film pendek dilaksanakan pada tanggal 27 Desember 2018 di beberapa RT kelurahan Sambutan. Penyuluhan kesehatan dimaksudkan untuk meningkatkan pengetahuan masyarakat tentang rokok dan bahaya merokok baik sebagai perokok aktif maupun perokok pasif. Masyarakat yang hadir sangat antusias yang ditunjukkan dengan aktif bertanya atas materi yang disampaikan. Berdasarkan hasil evaluasi, 4 dari 5 (80\%) masyarakat dapat menjawab dengan tepat dan menjelaskan kembali definisi, penyebab, bahaya yang dapat ditimbulkan oleh rokok serta dapat menyebutkan cara - cara yang dapat dilakukan untuk berhenti merokok. Penyuluhan ini juga diharapkan dapat menjadi awal untuk meningkatkan kesadaran masyarakat untuk berhenti merokok dengan mencari bantuan untuk berhenti merokok, salah satunya dengan terapi SEFT. 


\section{Terapi SEFT}

Pelaksanaan terapi SEFT sebagai terapi berhenti merokok dilakukan pada tanggal 28 Desember 2018 pada pukul 08.0012.30 wita yang dipusatkan di RT 13 kelurahan Sambutan kota Samarinda. Kegiatan ini berhasil melakukan terapi pada 10 orang yang merupakan perokok berat yang sudah merokok lebih dari 10 tahun dan mengkonsumsi lebih dari 1 bungkus perhari.

2 dari $10(20 \%)$ responden merupakan perokok berat dengan riwayat merokok lebih dari 10 tahun. Saat dilakukan terapi SEFT responden mengatakan merasa badan terasa nyaman. Selain itu pikiran terasa lebih tenang. Setelah dilakukan terapi SEFT, responden diminta untuk merokok, 1 responden mengatakan bahwa rokok yang dihisapnya terasa pahit sedangkan responden lainnya merasa mual.

Hasil penelitian lainnya didapatkan dari 5 responden dengan kategori perokok sedang dengan riwayat merokok 1-5 tahun. Seluruh responden mengakatan bahwa setelah dilakukan terapi mereka merasa bahwa merokok bukan sesuatu yang menyenagkan lagi. Pada saat dipersilahkan merokok 3 dari 5 responden mengatakan merokok tidak enak, mulut terasa pahit dan 2 lainnya terlihat batuk saat merokok.

Respoden lainnya (3 responden) merupakan perokok ringan dengan riwayat merokok $<1$ tahun. Responden ini melaporkan bahwa setelah dilakukan terapi SEFT, mereka mengatakan badan terasa lebih nyaman dan lebih semangat.

Hasil kegiatan ini membuktikan bahwa terapi SEFT dapat mengurangi intensitas kebiasaan merokok peserta. Peserta terapi mengatakan bahwa setelah terapi ia merasa rokok itu adalah bahan yang berbahaya dan tidak bermanfaat bagi tubuhnya. Pada saat peserta diminta untuk merokok, mereka mengatakan rokok yang dihisapnya terasa pahit, sebagian mengeluh mual dan rasa ingin muntah, bahkan ada peserta yang muntah. Hal ini membuktikan bahwa kesadaran diri dapat merubah persepsi seseorang tentang sesuatu dalam hal ini rokok.

SEFT sebagai terapi yang menyebabkan kondisi tubuh seseorang relaksasi, dimana relaksasi dapat menghasilkan efek fisiologis yang bertolak belakang dari efek akibat kecemasan seperti denyut jantung menurun, aliran darah meningtkat dan stabilitas neuromuskular (Kaplan, Sadock, \& Grebb, 1997). Kondisi ini yang menyebabkan gelombang otak sesorang menjadi menurun, yang awalnya $\beta$ menjadi $\alpha$. Sehingga kondisi ini memudahkan para terapis untuk memasukkan informasi ke alam bawah sadar untuk mengubah persepsi rokok dan kebiasaan merokok. Terapi SEPT juga memasukkan konsep spiritual dan do'a didalam terapi, hal ini memungkinkan seseorang lebih cepat menjadi relaksasi serta mudah menerima sugesti yang sifatnya mengajak untuk mengingatkandan berdizikir hanya kepada Allah SWT.

\section{SIMPULAN}

Berdasarkan hasil kegiatan pengabdian kepada masyarakat ini dapat disimpulkan :

1. Jumlah perokok di kelurahan Sambutan kota Samarinda masih tinggi. Berdasarkan hasil pengumpulan data dari $845 \mathrm{KK}$ didapatkan $420 \mathrm{KK}(48,4 \%)$ yang minimal memiliki satu orang anggota keluarganya yang merokok dan mayoritas $(49,05 \%)$ menghabiskan 1 bungkus perhari dengan lama merokok terbanyak lebih dari 10 tahun $(62,4 \%)$.

2. Penyuluhan kesehatan dapat meningkatkan pengetahuan masyarakat tentang bahaya rokok dan diharapkan dapat meningkatkan kesadaran masyarakat untuk berperilaku sehat dengan berhenti merokok.

3. Terapi SEFT dirasakan oleh masyarakat dapat mengubah persepsi masyarakat tentang rokok. Merokok yang sebelumnya terasa nyaman, namun setelah terapi SEFT, rokok menjadi pahit dan terasa mual. Sehingga dengan kata lain terapi SEFT dapat menurunkan intensitas 
kebiasaan merokok di kelurahan Sambutan kota Samarinda.

\section{DAFTAR PUSTAKA}

Blaise, C. F., Suriadi, \& Hafizah, R. (2015). Efektifitas terapi SEFT (spiritual emotional freedom technique) terhadap penurunan intensitas merokok di klinik berhenti merokok UPTD puskesmas kecamatan Pontianak kota. Proners, $3(1), 1-10$.

Budianto, Z. (2015). Efektivitas spritual emotional freedom technique ( SEFT ) untuk mengurangi frekuensi kekambuhan penyakit migrain. JIPT, 03(02), 215-248.

Fawzani, N., \& Triratnawati, A. (2005). Terapi berhenti merokok. Makara, 9(1), 1522.

Kaplan, H. ., Sadock, B., \& Grebb, J. . (1997). Sinopsis psikiatri. Jakarta: Binapura Aksara.

Kemenkes RI. (2015). Perilaku merokok masyarakat Indonesia berdasarkan riskesdas 2007 dan 2013. Infodatin, 111.
Riska, D. W. (2016). Implementasi perwalikota Samarinda nomor 51 Tahun 2012 tentang kawasan tanpa rokok ( KTR pada puskesmas rawat inap Palaran. Administrasi Publik, 4(2), 4174-4188.

Sulifan, Y., \& Muhid, A. (2014). Efektifitas terapi SEFT ( Spiritual Emotional Freedom Technique ) untuk mengurangi perilaku merokok remaja madya, 9(1), 86-95.

Zainudin, A. F. (2012). SEFT for healing, success, happiness, greatness. Jakarta: Afzan Publishing. 